\title{
Critical Thinking in Higher Education: A Pedagogical Look
}

\author{
Mansoor Fahim \\ Islamic Azad University - Science and Research Branch, Tehran, Iran \\ Email: dr.manfahim@yahoo.com \\ Nima Shakouri Masouleh \\ Islamic Azad University - Science and Research Branch, Tehran, Iran \\ Email: nima.shakouri2011@Gmail.com
}

\begin{abstract}
Many authorities in higher education did not enthusiastically embrace the idea that college students should receive explicit instruction in how to think. Note that the academic community was opposed to good thinking, but many educators believed that it was a misguided effort. For example, Glaser (1984) cited abundant evidence of Critical Thinking failures in support of his argument that thinking skills are contextbound and do not transfer across academic domains. Glaser and other sceptics were partly correct. Better thinking is not a necessary outcome of traditional, discipline-based instruction. But, increasingly global relationships of culture, people and economic activity make Critical Thinking as necessary as sunrise. This study attempted (1) to examine the predictive relationships of student dispositions and their abilities to think; and (2) to open a refreshed horizon in teaching students to develop their ability of Critical Thinking. Furthermore, the authors believed that to motivate students' disposition, it is indispensable for the teacher to scaffold them to think critically.
\end{abstract}

Index Terms —critical thinking, disposition, critical pedagogy, Socratic questioning

\section{INTRODUCTION}

Preparing students to be able to think critically is a goal of many professionals in higher education and also a quality sought by employers of university graduates. Students' ability to think critically has become a major concern among educators and psychologists as they try to study the factors influencing the acquisition of thinking skills. Therefore, Critical Thinking skill is considered an important variable in the process of students' learning. This study attempts to examine the predictive relationships of student dispositions and their abilities to think critically. The ability to think critically is important among students in higher education as the content of education at this level requires higher order thinking such as the ability to apply critical evaluation and give evidence for their opinions. Students seem satisfied with their initial interpretations of what they have read and seem genuinely puzzled at requests to explain or defend their point of view. As a result, responses to assessment items requiring explanations of criteria, analysis of texts or defense of a judgmental point of view were disappointing. Few students could provide more than superficial responses to such tasks, and even the "better" responses showed little evidence of well problem-solving or Critical Thinking skills. However, Critical Thinking is often seen as a universal goal of higher education. The writers see disposition of students to think critically as a prerequisite condition. Besides, providing the pedagogy of Critical Thinking, the writers attempted to provide the theoretical background of Critical Thinking.

\section{LITERATURE REVIEW}

\section{A. Theoretical Background}

The literature on Critical Thinking has roots in two academic disciplines: philosophy and psychology (Lewis \& Smith, 1993). Sternberg (1986) has also noted a third Critical Thinking strand within the field of education (cited in Lai, 2011). These separate academic strands, as Lai (2011) claims, have developed different approaches to defining Critical Thinking from different perspectives: the philosophical approach, the cognitive psychological approach, and educational approach (Lai, 2011). The writings of Socrates, Plato, Aristotle, and more recently, Matthew Lipman and Richard Paul, exemplify the philosophical approach. This approach focuses on the hypothetical critical thinker, enumerating the qualities and characteristics of this person rather than the behaviors or actions the critical thinker can perform. Those working within the philosophical tradition also emphasize qualities or standards of thought. For example, Bailin (2002) defines Critical Thinking as thinking of a particular quality - essentially good thinking that meets specified criteria or standards of adequacy and accuracy. Further, the philosophical approach has traditionally focused on the application of formal rules of logic. Two of the definitions of Critical Thinking emerged from the philosophical tradition include those proposed by McPeck (1981) and Ennis (1985) respectively: "the propensity and skill to engage in an activity with reflective 
skepticism" (cited in Lai, 2011, p. 6) and "reflective and reasonable thinking that is focused on deciding what to believe to do" (cited in Lai, 2011, p.6). Conversely, the cognitive psychological approach, particularly those immersed in the behaviorist tradition and the experimental research paradigm, tend to focus on how people actually think versus how they could or should think under ideal conditions. Furthermore, rather defining Critical Thinking by pointing to characteristics of the ideal thinker or enumerating criteria or standards of good thought, those working in cognitive psychology tend to define Critical Thinking by the types of actions or behaviors critical thinkers can do; they more or less take a reductionist procedure. Typically, this approach to defining Critical Thinking includes a list of skills or procedures performed by critical thinkers (Lewis \& Smith, 1993). The third approach to Critical Thinking is educational. Those working in the field of education have also participated in discussions about Critical Thinking. Benjamin Bloom and his associates, as Lai (2011) argues, are included in this category. Their taxonomy for information for information processing skills is one of the most widely cited sources for educational practitioners when it comes to teaching and assessing higher-order thinking skills. Bloom's taxonomy is hierarchical, with "comprehension" at the bottom and "evaluation" at the top. The three highest levels (analysis, synthesis, and evaluation) are frequently said to represent Critical Thinking (Kennedy, Fisher, \& Ennis, 199, cited in Lai, 2011, p. 8).

\section{B. What Is Critical Thinking?}

What the Critical Thinking movement has emphasized is the idea that specific reasoning skills or strategies undergird the curriculum as a whole. In a sense, Critical Thinking refers to the use of cognitive skills or strategies that increase the probability of a desirable outcome. In fact, the idea of rationality is the corner stone of Critical Thinking. To Critical Thinking, the critical person is something like a critical consumer of information; he or she is driven to seek reasons and evidence. To do that, one must be mastered certain skills of thought in order to be able to scaffold his/her ideology. Halpern (1999) maintains, "The ability to judge the credibility of an information source has become an indispensable Critical Thinking skill that needs to be deliberately and repeatedly taught in college and earlier" (p. 71). Accordingly, Paul (1994) draws a distinction between weak and strong sense of Critical Thinking. For him, the former means that one has learned the skills, while the latter means that one has incorporated these skills into a way of living in which one's own assumptions are re-examined and questioned as well. Paul believes that, because Critical Thinking allows us to overcome the sway of our egocentric and sociocentric beliefs, "it is essential to our role as moral agents and as potential shapers of our own nature and destiny" (Paul 1990, p. 67). It goes without saying that Critical Thinking is considered to be as reasonable reflective thinking focused on deciding what to believe or to do; the assumption is that logical deciding usually leads to affective doing. Wood (2002) says Critical Thinking is the process of using reasoning to discern what is true, and what is false. Accordingly, Critical Thinking is seen as an essential skill for success in our society and has been heralded as a need in achieving our goals in most curriculum analyses.

\section{Who Is a Critical Thinker?}

There are lots of questions obsessing every intellectual mind: Why are some people better than others at solving problems and making decisions? Why are some people better than others at supporting their beliefs and actions with good reasons? The answers may seem obvious. Some people are cleverer than others. But is being clever enough? For the latter question, it seems some people have more knowledge or are more eloquent than others. Still, two equally intelligent people can be equally articulate and knowledgeable, but not be equally good thinkers. If only one of them is thinking critically, that one will be better at analyzing and evaluating facts and opinions, sources and claims, options and alternatives. Accordingly, Carroll (2004) maintains:

The critical thinker will be a better problem-solver and better decision-maker. When we're thinking critically, we're using our knowledge and intelligence effectively to arrive at the most reasonable and justifiable position possible. When we're thinking uncritically — no matter how intelligent or knowledgeable we are - we'll make unreasonable decisions and arrive at unreasonable beliefs or take unjustifiable actions, unless we are lucky and end up making the right choice for the wrong reasons! (p. 2)

Carroll (2004) further adds that a critical thinker is neither dogmatic nor gullible. The most distinctive features of the critical thinker's attitude are open-mindedness and skepticism. Being open-minded means being willing to examine issues from as many sides as possible, looking for the good and bad points of the various sides examined. In fact, critical thinker must cultivate a sense of healthy skepticism along with an ability to be open-minded, especially when considering viewpoints contrary to one's own. Critical Thinking does not mean being argumentative or being critical of others. However, too much skepticism leads to doubting everything and committing oneself to nothing; too little skepticism leads to gullibility. Ultimately, in order to function in the world, we have to accept the probability that at least some things are as they seem. This requires trust. If we can analyze clearly the basis of what we take as true, we are more able to discern when it is reasonable to be trusting and where it is useful to be sceptical. Ennis (1987) identified a range of dispositions and abilities associated with Critical Thinking. These focused on: the ability to reflect sceptically; and the ability to think in a reasoned way:

Scepticism in Critical Thinking means bringing an element of polite doubt. In this context, scepticism doesn't mean you must go through life never believing anything you hear and see. That would not be helpful. It does mean holding open the possibility that what you know at a given time may be only part of the picture. (cited in Cottrell, 2005, p.2) 
Accordingly, Cottrell (2005) implies a Critical Thinking is a tool for a critical thinker to use scepticism and doubt constructively so that he/she can analyze what is before him/her.

\section{Critical Thinking Development}

Halpern (1998) proposes a four-part model of instruction for Critical Thinking. Not surprisingly, it includes two parts we have sparsely discussed-instruction in the skills and dispositions for Critical Thinking - but it also includes structure training and metacognitive monitoring. With structure training, students are taught to create retrieval cues from the structural aspects of a problem or an argument so that when these structural aspects are present in the novel context, they can serve as cues for retrieval. Metacognition is usually defined as "what we know about what we know." In fact, metacognitive monitoring is determining how we can use this knowledge to direct and improve the thinking and learning process. While engaging in Critical Thinking, students need to monitor their thinking process, checking that progress is being made toward an appropriate goal, ensuring accuracy, and making decisions about the use of time and mental effort. To enhance Critical Thinking, students need to develop the ability to critically evaluate the work of others (Cottrell, 2005).

\section{E. Critical Pedagogy}

In the language of Critical Pedagogy, the critical person is one who is empowered to seek justice, to seek emancipation. Not only is the critical person adept at recognizing injustice but, for Critical Pedagogy, that person is also moved to change it. Here Critical Pedagogy wholeheartedly takes up Marx's Thesis, that the philosophers have only interpreted the world, in various ways; the point, however, is to change it. For Paulo Freire (1985), Critical Pedagogy is concerned with the development of "critical consciousness" (cited in Monchinski, 2008, p. 4). Freedom, for Freire, begins with the recognition of a system of oppressive relations, and one's own place in that system. The task of Critical Pedagogy is to bring members of an oppressed group to a critical consciousness of their situation as a beginning point of their liberatory praxis. Praxis involves theorizing practice and practicing theory. Critical Pedagogy considers a continuous relationship between practice and theory which involves a constant give-and-take of practice by theory and theory by practice. As Freire (1985), eloquently notified, "Cut off from practice, theory becomes a simple verbalism and separated from theory, practice is nothing but blind activism" (cited in Mochinski, 2008, p. 2).

The very basic and fundamental aspect of Critical Pedagogy is the sharp and meticulous distinction which is made between the banking system of education and the problem-posing education. The banking system of education sees students as empty vessels waiting to be filled with information by knowledgeable teachers. Students are viewed as passive sponges waiting to soak up facts. Teachers in this model are viewed as "bank-clerks" who make deposits into empty students. The banking system of education is a mechanistic conception of education. It fits well with the assumptions of behaviorist learning theories (Monchinski, 2008). The two main characteristics of banking system of education could be defined as that the teacher knows everything and the student knows nothing and the teacher talks and the students listen. In fact, in a banking concept of education a "culture of silence" exists. In these classrooms students feel what they say isn't or won't be considered important. This may lead to the "mutism" where students in classrooms avoid dialogue in favor of becoming silent. Mutism and a culture of silence signify oppression and dehumanization in classrooms. On the other hand, as direct opposition to the banking system of education, problem posing education as one form of the realization of Critical Pedagogy in classroom context encourages Critical Thinking. One of the teachers' roles in a problem-posing education is to "problematize situations" by presenting to students situations with which they are familiar but in a way that make them thinking about those situations in new ways.

\section{F. Critical Thinking and Critical Pedagogies}

Critical Thinking and Critical Pedagogy share in two features: The concept of criticality and dialogical thinking. Criticality requires one to do something, whether that something refers to seeking reasons or seeking social justice. For Paulo Freire, criticality requires praxis - both reflection and action, both interpretation and change. As he puts, "Critical consciousness is brought about not through intellectual effort alone but through praxis - through the authentic union of action and reflection" (Freire 1970, 48).

Another feature that these two - critical theory and Critical Pedagogy — share is what Paul (1983) called 'dialogic thinking' which is inherent to Critical Thinking. Nevertheless, regarding Critical Pedagogy, the social dimension of dialogue is emphasized within Critical Pedagogy: dialogue occurs between people, not purely as a form of dialogical thought. Here again Critical Pedagogy focuses more upon relations between individuals, where Critical Thinking's focus is more on the individuals themselves. To better appreciate the concept of dialogue within Critical Pedagogy, let me put another way, being in contact with others is one absolute necessity for having a dialogue. This contact, of course, may indirectly involve others - the so called dialogic thinking. However, Vygotsky claims that the development of such capacities for individuals necessarily involves social interactions as well. Interaction is valued as a vehicle for developing, through mentoring, the Critical Thinking skills of students (Duffy, Dueber, \& Hawley, 1998). Paul addresses this point, but it does not play the central role in his theory that it does for Freire and other Critical Pedagogues (Burbules \& Berk, 1999). The method of Critical Pedagogy for Freire involves, to use his phrase, "reading the world" as well as "reading the word" (Freire \& Macedo 1987). Dialogue is essential to the implementation of Critical Pedagogy in the everyday classroom. In fact, for dialogue to be a method of true knowledge, the knowing 
subjects must approach reality scientifically in order to seek the dialectical connections which explain the form of reality. In this important regard, Burbules and Berk (1999) hold Critical Pedagogy and Critical Thinking arise from the same sentiment to overcome ignorance, to test the distorted against the true, to ground effective human action in an accurate sense of social reality.

\section{G. Disposition and Critical Thinking}

What kind of a person would be apt to use their Critical Thinking skills? The experts poetically describe such a person as having "a critical spirit." Spirit can be defined as "an inclination or tendency, mood or emotional state" (American Heritage $®$ Dictionary, 2000). Spirits can denote a disposition, affect or frame of mind, i.e. in high or low spirits. Having a critical spirit does not mean that the person is always negative and hypercritical of everyone and everything. The experts use the metaphorical phrase critical spirit in a positive sense. By it they mean "a probing inquisitiveness, a keenness of mind, a zealous dedication to reason, and a hunger or eagerness for reliable information" (Facione, 2011, p. 10). Accordingly, Facione (1990) holds, "A critical spirit suggests a positive effect that transcends normal thinking and can assist us in transforming our thinking" (p. 13). Also, about the importance of disposition, Halpern (1999) claims:

It is not enough to teach college students the skills of Critical Thinking if they are not inclined to use them. Critical Thinking is more than the successful use of the right skill in an appropriate context. It is also an attitude or disposition to recognize when a skill is needed and the willingness to exert the mental effort to apply it. (p. 72)

Sears and Parsons (1991) call these dispositions the ethic of a critical thinker (cited in Halpen, 1999, p. 72). Accordingly, lazy or sloppy thinkers may have a large repertoire of Critical Thinking skills but not be inclined to use any of them. No one can develop expertise in any area without engaging in the effortful processes of thinking (Wagner, 1997, cited in Halpen, 1999). Thus we need to find ways to make students value good thinking and the work that is needed to achieve that goal.

Critical Thinking is best developed through an engagement with different areas of knowledge rather than as an autonomous skill to be taught in itself. However, teaching content and skills is of minor import if learners do not also develop the dispositions or inclination to look at the world through a critical lens (Burbules, \& Berk, 1999). Thus, Critical Thinking in this way requires a critical person to have both the capacity and the disposition to seek reasons, truth and evidence. Dispositions, unlike skills, cannot be taught; they can only be cultivated through such activities as modeling (Reece, 2002). A Critical Thinking disposition suggests a mind frame or inclination to use Critical Thinking.

Critical thinking dispositions include a willingness to take a position and defend it, showing creativity, flexibility, perseverance, reflection, and maturity in judgments, and being truth-seeking, systematic, and showing maturity in judgments (Facione, 1990). These have also been described as critical thinking indicators which also includes selfawareness, genuineness, and being self-disciplined (Alfaro-LeFevre, 2004). Furthermore, Critical Thinking is dependent upon a person's disposition to use it (Paul, 1983). Disposition to think critically can be defined as consistent willingness, motivation, inclination and an intention to be engaged in Critical Thinking while reflecting on significant issues, making decisions and solving problems (Facione, Sanchez, Facione, \& Gainen, 1995). According to Zoller, Ben-Chaim and Ron (2000), a student's disposition to think critically is a necessary pre-condition for Critical Thinking and greatly affects Critical Thinking capability. Experts continue to agree that Critical Thinking includes the dimensions of skill and disposition (Dewey 1933; Norris and Ennis, 1989).

Teaching students to think critically must include allowing them to come to their own conclusions. Implicitly, it is an obligation for a teacher to scaffold students in order that they he/she can provide an effective program for developing Critical Thinking which creates a culture of thinking in the classroom. To do that, (1) teachers' program should provide models of good reasoning behavior. The purpose of the models criterion is to make sure that students are provided with exemplars of what thinking dispositions look like in practice; (2) the program should also provide direct explanations about the purpose, concepts and methods of good reasoning. In other words, students should be told why good reasoning is important, and directly taught some key reasoning concepts and moves; (3) a program for teaching reasoning should provide plenty of opportunity for peer interaction around reasoning. These are interactions in which students reason together, discuss reasoning with one another, evaluate reasoning together, and so on. The purpose of this criterion is to bring the thinking disposition alive for the student by anchoring it in meaningful interpersonal interactions; and (4) last but certainly not least, the program should provide plenty of opportunities for formal and informal feedback around thinking dispositions. Through teacher feedback, peer feedback, and self feedback, students should learn about the strengths and weakness of their reasoning behavior. Furthermore, students must be brought to criticality, and this can only be done by alerting them to the social conditions that have brought this about. In short, we can restate the problem as follows: Critical Thinking's claim is, at heart, to teach how to think critically.

\section{H. How to Enhance Students' Critical Thinking}

All education consists of transmitting to students two different things: (1) what to think and (2) how to think. We do excellent job of the former; however, we have failed to teach students to think critically about the content presented to us (Schafersman, 1991). If we do not teach students how to think critically, we implicitly lead them to harmful thinking — notably, illogical thinking and emotional thinking. The former is realized as fallacious reasoning supported by inadequate or unreliable reasoning; and the latter, emotional thinking which relies on emotions to search for and 
discover truth or knowledge. Critical Thinking involves that one rejects opinions and conjectures that have been shown to be wrong.

It is undisputable that children are not born with the power to think critically. It is a learned ability that must be taught. Humans are conditioned from birth to follow authority figures and not to question them as the goal of education is to instill traditional values like the respect for authority, perseverance, fidelity to duty, consideration of others and practicality. Such conditioning is done by parents and teachers using a wide variety of positive and negative reinforcement techniques. The result of such conditioning is in contrast with the thesis of both scientific investigation and Critical Thinking. To develop the ability of thinking critically, the following strategies are suggested: (1) annotating, which refers to underlining key word, writing comments, making questions in the margins, making notes of anything that strikes you as interesting, bracketing important parts, or highlighting the important parts; (2) previewing which helps one to have a preconception of what the text is about and how it is formatted. Thus, a critical thinker is suggested to skim the text and take a look at the pictures (if provided), titles of the passage to grasp a tacit understanding of the text; and (3) contextualizing that refers to the notion that when one reads a text, it is critical for him/her to read it from his/her lens. Thinking will be critical if the students provide a link between what is in their background and what is in the text. In effect, this implies the communicative perspective that meaning does not reside in the text but in the mind of the students. We believe these three strategies can be consolidated if they are accompanied by making Socratic questions on the part of students; and reinforcing the students to express their thoughts. At first steps, the role of a teacher, as a scaffolder in the classroom interaction, is pivotal. For learners to be taught to be critical thinkers, teachers should help them to voice their words; that is, letting them talk from their vantage points. Gradually, teachers can stick to the margin, and acts as a facilitator of the process of learning. Here, Socratic questioning is gradually instilled by teachers. Socratic questioning can be used to pursue thoughts in many directions and for many purposes, including: to explore complex ideas, to get to the truth of things, to open up issues and problems, etc. The art of Socratic questioning is intimately connected with Critical Thinking because the art of questioning is important to excellence of thought. What the word "Socratic" adds to the art of questioning is systematicity and depth in assessing the facts and opinions. Both Critical Thinking and Socratic questioning share a common end. Both are in their pursuit of meaning and truth. In a nutshell, in teaching, teachers can use Socratic questioning for at least two purposes : (1) to help students begin to distinguish what they know or what they do not know; (2) to foster students' abilities to ask Socratic questions, to help students acquire the powerful tools of Socratic dialogue, so that they can use these tools in everyday life. To this end, teachers can model the questioning strategies they want students to emulate and employ. In fact, Critical Thinking through the employment of Socratic questioning teaches students to dig beneath the surface of ideas. It teaches us the value of developing questioning minds in cultivating deep learning. In the same line, some of the Socratic questions that if cautiously employed will certainly help students develop their Critical Thinking are as follows: (1) getting students to clarify their thinking e.g., 'Why do you say that?'; (2) challenging students about assumptions, e.g., 'Is this always the case?'; (3) alternative viewpoints and perspectives, e.g., 'What is the counter argument for?', and the most meticulous one (4) question the question e.g., 'Why do you think that I asked that question?'

\section{CONCLUSION}

Critical Thinking is best understood as the ability of thinkers to take charge of their own thinking. This requires that they develop sound criteria and standards for analyzing and assessing their own thinking and routinely use those criteria and standards to improve its quality (Ellis, 1997). Along the same line, Critical Thinking is a valuable skill that, once learned, can be applied in many different disciplines; however, researchers have contended that having mere skills doesn't guarantee Critical Thinking. Critical Thinking is an attempt to make a distinction between facts and opinions. In fact, Critical Thinking is deciding rationally what to or what not to believe. Critical Thinking involves, in part, the attitude of being disposed. In fact, the research indicated that there is a need for both skills and dispositions in curriculum models. Dispositions require students to be internally motivated or better to say be scaffold by their teacher so that they can think critically. We believe educational and professional success require nurturing one's consistent internal willingness to think as well as developing one's thinking skills. To do this, the teacher must provide students with as many models, opportunities, exemplars, and explanations as possible in order to help them operationalize their skills. In fact, having mere skills in order to think critically is not enough. The teacher should find ways in order to make students willing and disposed to think critically. One way suggested in this paper has been to enhance students' Critical Thinking by the strategies of annotating, previewing and contextualizing that work effectively if accompanied by Socratic questioning.

\section{REFERENCES}

[1] The American Heritage Dictionary of English Language. Boston: Houghton Mifflin Harcourt.

[2] Bailin, S. (2002). Critical thinking and science education. Science \& Education, 11(4), 361-375.

[3] Burbules, N., \& Berk, R. (1999). Critical thinking and critical pedagogy. In T. S. Popewitz \& L. Fender (Eds), Critical theories in education (pp. 45-66). New York: Routledge

[4] Carroll, R. T. (2004). Critical thinking. Retrieved in 2012, March, from http://www.scribd.com/doc/16426858/CriticalThinking-Ch1-Drrobert-Todd-Carroll

[5] Cottrell, S. (2005). Critical thinking skills: Developing effective analysis and arguments. London: Palgrave Macmilian. 
[6] Dewey, J. (1933). How we think: A restatement of the relation of reflective thinking to the education process. Boston: Heath.

[7] Duffy, T. M., Dueber, B., \& Hawley, C. L. (1998). Critical thinking in a distributed environment: A pedagogical base for the design of conferencing. CRLT Technical Report, 5 (98), 1-27

[8] Ellis, D (1997). Becoming a Master Student. Boston: Houghton Mifflin Co.

[9] Facione, P. A. (1990). Critical thinking: A statement of expert consensus for purposes of educational assessment and instruction. Millbrae, CA: The California Academic Press.

[10] Facione, P. A. (2011). Critical Thinking: Why it is and why it counts. Retrieved in 2012, March from www. insightassessment. com/content/download/1176/7580/

[11] Facione, P. A., Sanchez, C. A., Facione, N. C., \& Gainen, J. (1995). The disposition toward critical thinking. Journal of General Education, 44(1), 1-25.

[12] Freire, P. (1970). Pedagogy of the oppressed. New York: Continuum.

[13] Freire, P \&. Macedo, D. (1987). Literacy: Reading the word and the world. Westport, CA: Bergin \& Garvey.

[14] Halpern, D. F. (1999). Teaching for critical thinking: Helping college students develop skills and dispositions of a critical thinker. New Directions For Teaching And Learning, 80, 69-74.

[15] Lai, E. R. (2011). Critical thinking: A literature review. Retrieved in 2012, March, from www.pearsons.com/hai/.../CriticalThinkingReviewFINA

[16] Lewis, A., \& Smith, D. (1993). Defining higher order thinking. Theory into Practice, 32(3), $131-137$. doi:10.1080/00405849309543588

[17] Monchinski, T. (2008). Critical pedagogy and the everyday classroom. Boston: Springer.

[18] Morrow, R. A., \& Torres, C. A. (2002). Reading Freire and Habermas: Critical pedagogy and transformative social change. New York: Teachers College Press.

[19] Norris, S. P. (1985). Synthesis of research on critical thinking. Educational Leadership. 42 (8), 40-45.

[20] Norris, S. P., Ennis, R. H. (1989). Evaluating critical thinking. Teaching thinking. R. J. S. D. N. Perkins. Pacific Grove, CA: Midwest Publications.

[21] Paul, R. (1983). An agenda item for the informal logic / critical thinking movement. Informal Logic Newsletter, 5 (2), 23.

[22] Paul, R. (1990). Critical Thinking: What Every Person Needs to Survive in a Rapidly Changing World. Rohnert Park, CA: Center for Critical Thinking and Moral Critique.

[23] Paul, R. (1994). Teaching critical thinking in the strong sense. In S. K. Wlaters (Ed), Re-Thinking Reason: New Perspectives in Critical Thinking (pp. 181-198). Albany: SUNY Press.

[24] Reece, G. (2002). Critical thinking and transferability: A review of literature. Retrieved in 2011 from www.library.american.edu/.../critical_thinking.pdf

[25] Schafersman, S. D. (1991). An introduction to critical thinking. Retrieved in 2012, April, from facultycenter. ischool.syr.edu /wp-content/uploads/...

[26] Wood, R. (2002). Critical thinking. Retrieved in 2012 from ttp://www.robinwood.com/Democracy/ GeneralEssays/ CriticalThinking

[27] Zoller, U., Ben-Chaim, D. and Ron, S. (2000). The disposition toward critical thinking of high school and university science students: An inter-intra Israeli-Italian study. International Journal of Science Education 22 (6), 571-582.

Mansoor Fahim was a member of the faculty of English Language and Literature at Allameh Tabataba'i University in Tehran, Iran from 1981 to 2008 when he was retired as an associate professor of TEFL. He has taught English at a welter of universities. At present, he runs Research methods, Psycholinguistics, Applied Linguistics, Second Language Acquisition, and Seminar classes at M.A. level and First Language Acquisition, Psycholinguistics, and Discourse Analysis courses at Ph.D. level at a number of universities including Allameh Tabataba'i and Islamic Azad Universities. Moreover, he has several published articles and books mostly in the field of TEFL and has translated some books into Farsi. Dr. Fahim is currently a member of the editorial board of some Iranian journals of Applied Linguistic Studies.

Nima Shakouri Masouleh is currently a Ph.D. candidate of TEFL at Azad University, Science and Research, Tehran, Iran. He is also a faculty member of Islamic Azad University, in Guilan. He has taught English courses for over a decade at different universities in Guilan. Moreover, he has some published articles and books. 